\title{
Social power and emotional experience: Actor and partner effects within dyadic interactions
}

\author{
Carrie A. Langner, Dacher Keltner \\ University of California, Department of Psychology, Berkeley, CA 94720, USA
}

\begin{abstract}
A dyadic methodological and statistical approach to social power is used to test the notion that an individual's power and a partner's power have distinct effects on the individual's emotional experience. Two studies examined actor and partner effects of social power on emotion within dyadic interactions. Across interpersonal contexts and measures of social power, the individual's own social power, theorized to activate behavioral approach, was associated with positive emotion (an actor effect). In contrast, being subject to a partner's elevated social power, theorized to activate behavioral inhibition, was associated with increased negative emotion (a partner effect). The discussion focuses on how dyadic methodological and statistical approaches point to new lines of inquiry in the study of social power.
\end{abstract}

Keywords: Social power; Emotion; Dyadic processes

\section{Introduction}

Social power reflects the influence an individual exerts over his or her partner's outcomes through the allocation of resources and punishments (Dépret \& Fiske, 1999; French \& Raven, 1959; Keltner, Gruenfeld, \& Anderson, 2003; Lewin, 1951). Social power has been measured through self-reports, interaction partners' judgments, and experimental inductions, almost exclusively by focusing on the individual's own power (for a review, see Brauer $\&$ Bourhis, 2006). However, social power is inherently interpersonal; it is experienced by individuals in relation to interaction partners who also experience social power

We thank Annie Lin, Yun-Shan Lee, Jennifer Wu, Jennifer Kim, Lia Kraemer, Melissa Gordon-Wolston, and Zoe Cleland for assistance with data entry, and Cameron Anderson, Jennifer Berdahl, Serena Chen, Adam Cohen, Ariel Malka, Molly Parker Tapias and the UCSF Health Psychology postdoctoral group for their helpful feedback. The first author was supported by a Jacob K. Javits fellowship (Grant No. PI7B990019, 9/ 99-1/04) and a Ruth L. Kirschstein National Research Service Award (T32 MH019391-15).
(Thibaut \& Kelley, 1959). Although previous studies have examined the relationship between an individual's power and emotional response, no study to date has examined how both the individual's social power and the social power of others shapes emotion. In the present research, we examine how a partner's social power relates to an individual's emotions, testing hypotheses that within dyads the individual's power and the partner's power may operate in different ways.

\section{Dyadic approaches to social power}

Recent research has begun to examine social power within dynamic social interactions, moving beyond the level of the individual (Cook, 2001; Copeland, 1994; Guinote, Judd, \& Brauer, 2002; Overbeck \& Park, 2001; Tiedens, 2001; Vescio, Snyder, \& Butz, 2003). A dyadic approach starts from the assumption that a partner's social power is not merely the inverse of one's own social power (Lawler \& Bacharach, 1979). Individuals within relationships might both wield significant influence over one another, as in many romantic bonds (Acitelli, Kenny, \& Weiner, 2001). Or, two individuals might have little 
influence over one another, as when individuals do not depend on each other for resources. More typical, we suspect, are relationships that lie in between these two poles, where one individual has some degree of power over the other, but not in the absolute sense. Studies of social power, therefore, should examine the separate actor and partner effects of power, a line of inquiry made possible by advances in dyadic statistical approaches (Kenny, Kashy, \& Cook, 2007).

With respect to the study of social power and emotion, an actor effect refers to the effect of the individual's power on the individual's emotion independent of the partner's power. A partner effect refers to the effect of the partner's power on the individual's emotion independent of the individual's power. This distinction generates the central question of the present two studies: Are there separate actor and partner effects of social power upon emotional experience?

Past research on social power has focused primarily on actor effects of power. Experimental and role-based studies have operationalized high power as an individual's ability to influence a partner who in turn has limited ability to influence the high power individual (Berdahl \& Martorana, 2006; Chen, Lee-Chai, \& Bargh, 2001; Hecht \& LaFrance, 1998). Complementarily, low power has been operationalized as the lack of ability to influence a partner who has a great deal of influence. Although individuals' perceptions of power within these role assignments and experimental contexts no doubt varied across a continuum, past work has tended to treat power in zero-sum fashion-high power individuals have the power, and low power individuals have none-and very little research has examined partner power. A few studies have included low power conditions that primed the concept of a partner's influence over the individual (Galinsky, Gruenfeld, \& Magee, 2003, Studies 2 and 3; Guinote, 2007). However, no study to date has examined the independent effects of actor and partner power within a dyadic relationship.

\section{Approach/inhibition theory of social power}

According to approach/inhibition theory (Keltner et al., 2003), people with social power live in reward-rich environments, which activate approach tendencies. The approach system responds to rewards in the environment, readying the organism to approach and capitalize on these rewards (Carver \& White, 1994; Gray, 1987). Power has been shown to relate to approach-related cognition (Guinote, 2007) and behavior (Chen et al., 2001; Galinsky et al., 2003). As positive affect co-varies with approach activation (Ashby, Isen, \& Turken, 1999; Davidson, 1992), it was predicted to be associated with elevated social power (Keltner et al., 2003). Experimental studies have found that induced power is associated with behavioral activation (Galinsky et al., 2003) and positive emotion (Berdahl \& Martorana, 2006); other studies, it is important to note, have yielded mixed or null relationships between elevated power and positive emotion (Anderson \& Berdahl, 2002; Galinsky et al., 2003; Smith \& Trope, 2006). No study to date has separated the actor and partner effects of social power on positive emotion, which may yield more precise and robust relations between power and positive emotion than those previously observed.

Within approach/inhibition theory, reduced social power is associated with increased threats and constraints, which activate the tendency to inhibit. Behavioral inhibition, a system independent of behavioral approach (Carver \& White, 1994), manifests in a variety of behaviors oriented toward others in the environment who pose threats and the possibility of punishment, including patterns of social cognition (attention to those in power, sensitivity to threats) and social behavior (the inhibition of impulses according to beliefs about others' expectations). Negative affect co-varies with behavioral inhibition (Carver \& White, 1994), and was therefore hypothesized to be associated with reduced social power (Keltner et al., 2003).

Select studies support this hypothesis. Côté and Moskowitz (2002) found that low status individuals experienced more unpleasant mood compared to control and high status individuals. Hecht and LaFrance (1998) found that individuals with low power experienced more sadness and less happiness compared to those with equal or high power. However, it is unclear whether these effects are due to the actor's low power or the interaction partner's high power. The central aim of the present investigation was to address these ambiguities by identifying the distinct actor and partner effects of social power upon positive and negative emotion.

\section{Distinguishing actor and partner effects of social power on emotion}

How might actor and partner effects of power influence positive and negative emotion within dyads? Although approach/inhibition theory did not systematically address this question, its framework suggests that answers will be found in considering how actor and partner contributions to power dynamics relate to rewards, thereby influencing positive emotion, and threats, thereby driving negative emotion.

We reason that high actor power places the individual in a reward-rich environment, thereby activating approach tendencies and positive emotion. Having influence over one's partner within a relationship is likely to be rewarding, enabling the pursuit of goals and increasing the likelihood of social rewards directed at high power individuals (e.g., praise - see Keltner, Young, Heerey, Oemig, \& Monarch, 1998). Low partner power (a partner's lack of influence on the individual) may not necessarily be rewarding, and so we argue that it is the actor's power, rather than a partner's lack of power, that is related to positive emotion. Consistent with this reasoning, past research conducted at the individual level indicates that the experience of 
power over others (actor power), and not the lack of a partner's influence (low partner power), is associated with behavioral activation (Galinsky et al., 2003), which suggests that actor power should be associated with positive emotion. Given this reasoning, we predicted an actor effect of power on positive emotion independent of partner power.

In contrast, a partner's elevated social power is a likely source of threat and constraint, through the potential for evaluation, delivery of punishments, and withholding of rewards. By implication, the partner's elevated power should be associated with the individual's increased inhibition and negative emotion. Not having power over a partner (low actor power), on the other hand, does not necessarily translate to constraint and inhibition, because that partner may also have low power. Similarly, an actor with high social power could feel constrained by a powerful partner despite also having control over that partner. We therefore predict that being the subject of a partner's elevated social power (and associated threats and constraints) will be associated with behavioral inhibition, as indexed in increased negative emotion.

In the present two studies, we test the predictions that the individual's social power will be associated with elevated positive emotion (an actor effect), and that being subject to a partner's elevated social power will be associated with increased negative emotion (a partner effect). These predictions treat positive and negative emotions as orthogonal systems (e.g., Watson, Clark, \& Tellegen, 1988, but see Cacioppo \& Berntson, 1994). We test these predictions across two different types of dyadic relationships: Romantic partners with varying levels of influence over one another (Study 1) and strangers assigned to high and low power roles within a laboratory experiment (Study 2). In the current work, we examine both self-perceptions of power and other-perceptions of power (Anderson \& Galinsky, 2006; Emerson, 1964).

\section{Study 1: Social power and emotion in romantic relationships}

In the context of romantic partners' interactions, we examined two sources of social power: The partner's perception of the individual's power (to assess actor effects) and the individual's perception of their partner's power (to assess partner effects). Other individuals' perceptions of an individual's power act as important determinants and constraints upon that person's power (Butler \& Geis, 1990; Emerson, 1964). A powerful individual derives his or her power to a significant extent from others' ascriptions of power to that individual, and the ability to act in a fashion that justifies an elevated position of power. We predicted that the individual's power would positively correlate with the individual's experience of positive emotion (an actor effect), whereas the partner's power would positively correlate with the individual's experience of negative emotion (a partner effect).

\section{Methods}

\section{Participants}

Sixty heterosexual couples at a Midwestern university were recruited by advertisements and paid to participate in a larger study of couple interaction style. Participants were an average of 20 years old $(S D=1.9)$ and were European American. Average length of dating was 21.9 months $(S D=13.9)$, with a range of 6 months to 5 and a half years. One dyad was dropped from analyses due to missing data.

\section{Procedures}

Romantic partners arrived at the session together and were seated across from one another at a table in view of two video cameras. At the beginning of the session, participants filled out a questionnaire including baseline emotional experience reports and ratings of their partner's influence within the relationship. The couples were instructed to complete six directed discussions. Discussion topics included: The events of the day, a couple narrative ("how we met"), a conflict in the relationship (a conflict that had been listed by both members of the couple on an earlier questionnaire), an issue of concern (for each partner), a good event (for each partner), and a teasing interaction. For the teasing interaction, participants were each given a set of initials (e.g., "A.D.") and instructed to create a nickname and a story for their partner based on that set of initials (for a detailed description of the teasing exercise, see Keltner et al., 1998). All participants were given $90 \mathrm{~s}$ to create the tease, and $60 \mathrm{~s}$ to deliver the tease.

\section{Measures}

Power measure. Power was measured by each partner's estimate of her or his partner's influence on herself or himself using items from the Strength subscale of the Relationship Closeness Inventory (Berscheid, Snyder, \& Omoto, 1989). The influence scale included items such as, "my partner influences important things in my life", and "my partner influences how I spend my free time." Each item was rated from 1 ("strongly disagree") to 7 ("strongly agree") where higher scores reflect more influence. The 27 influence items were aggregated $(\alpha=.85)$. Because each partner rated the other, this measure creates two perspectives with which power can be examined in the relationship: The participant's perception of his or her partner's influence (a partner effect of power) and the partner's estimate of the participant's influence in the relationship (an actor effect of power). Actor and partner effects of power were represented in path models as the paths from the individual's power to the individual's emotion and the paths from the partner's power to the individual's emotion, respectively. Male participants rated their partners as more influential $(m=4.11, \quad S D=.72)$ than did female participants $(m=3.75, S D=.79, t=-2.65, r=.24, p<.05)$.

Emotion composites. After each discussion, participants rated the amount of emotion they experienced during the 
discussion on a scale from 0 ("no emotion") to 8 ("extreme emotion"). Discrete emotion items relevant to interactions between romantic partners (e.g., arousal, tension) were generated by the second author. Categorization of items as positive or negative was determined with principal components analysis with varimax rotation (see Table 1 for items and factor loadings). The size of the first two eigenvalues and the scree plot (Cattell, 1966) suggested two factors and explained $64 \%$ of the variance. Positive and negative emotion composites were created by averaging ratings across baseline and all discussions. Across the 10 measurement timepoints, positive and negative emotion composites demonstrated high internal reliability $(\alpha=.85$, $m=3.60, S D=1.30 ; \alpha=.94, m=1.18, S D=0.78$, respectively). Additionally, within each discussion the positive and negative emotion composites were reliable (average $\alpha=.89$; average $\alpha=.77$, respectively). The positive and negative emotion composites were moderately positively correlated $(r=.26, p<.05)$.

Interdependence of dyadic data. The correlation between partners' power scores within dyads was assessed $(r=.24$, $p=.07)$ and met the suggested nonindependence significance test of $p<.20$; we therefore tested our hypotheses with the use of dyadic statistical analyses (Kenny et al., 2007).

Table 1

Study 1: Positive and negative emotion composites

\begin{tabular}{lcc}
\hline Discrete emotions & Factor loading (I) & Factor loading (II) \\
\hline Positive & & \\
Amusement & .00 & .73 \\
Arousal & .30 & .69 \\
Happiness & .00 & .84 \\
Love & .00 & .77 \\
Pride & .14 & .83 \\
Negative & & \\
Anger & .84 & .00 \\
Anxiety & .76 & .27 \\
Contempt & .37 & .00 \\
Discomfort & .83 & .10 \\
Disgust & .77 & -.16 \\
Embarrassment & .82 & .17 \\
Fear & .80 & .19 \\
Guilt & .81 & .00 \\
Sadness & .83 & .00 \\
Shame & .82 & .00 \\
Tension & .78 & .27 \\
Cross-loaded & & \\
Desire & .36 & .82 \\
Concern & .79 & .34 \\
Sympathy & .62 & 3.41 \\
Eigenvalues & 8.63 &
\end{tabular}

Note. The item "shy" was also measured in the questionnaire but was not included in the factor analyses with emotion words because shyness is a behavioral trait (Cheek \& Melchior, 1990). The item "contempt" was not included in the negative composite because its factor loading was notably lower than all of the other negative emotion factor loadings. Items having cross-loadings higher than .32 were not included in the composites (Costello \& Osborne, 2005; Tabachnick \& Fidell, 2001).
Path analyses were conducted with AMOS 4 (Arbuckle, 1994). Maximum likelihood estimation was used to generate parameters, and the models were fit to covariance matrices. Dyads were treated as distinguishable on the basis of gender and paths for male and female partners were constrained to be equal. We did not hypothesize that the relationship between power and emotion would differ across gender and so we constrained the model to hold this relationship equal for women and men. Estimating path models based on the model introduced by Gonzalez and Griffin (1999) wherein dyads are treated as distinguishable on the basis of gender produced the same pattern of results.

\section{Results}

\section{Positive emotion}

A path analysis was designed in which both partners' other-rated power scores predicted their own positive emotion and the partner's positive emotion (Fig. 1). The positive emotion model fit the data well $\left(\chi^{2}(2)=.401, p=.82\right.$, Tucker-Lewis Index $(\mathrm{TLI})=1.254$, root mean square error of approximation (RMSEA) $=.000$ ). The overall withinpartner path was significant, indicating that, the more power an individual had, as reported by their romantic partners, the more positive emotion the individual experienced (an actor effect). In an additional model with a multiplicative term, the parameter from the interaction of actor and partner power to emotion was not significant.

\section{Negative emotion}

Next, a path analysis was designed in which both partners' other-rated power scores predicted both their own negative emotion and the partner's negative emotion (Fig. 1). The negative emotion model fit the data well $\left(\chi^{2}(2)=1.23, \quad p=.54, \quad\right.$ TLI $=1.135, \quad$ RMSEA $\left.=.000\right)$. The cross-partner path was significant, indicating that the more power the partner had, as estimated by the participant, the more negative emotion the individual reported (a partner effect). In an additional model with a multiplicative term, the parameter from the interaction of actor and partner power to emotion was not significant.

\section{Discussion}

Examining social power within a romantic relationship yielded initial evidence of differential relationships between actor and partner sources of power on emotion. As predicted, the actor's social power, as estimated by the partner, related to increased positive emotional experience, whereas the partner's social power, as estimated by the participant or actor, related to the individual's increased negative emotional experience. Those individuals whose partners reported them as wielding more influence experienced more positive emotion across six different conversations. Individuals who reported being more influenced by 

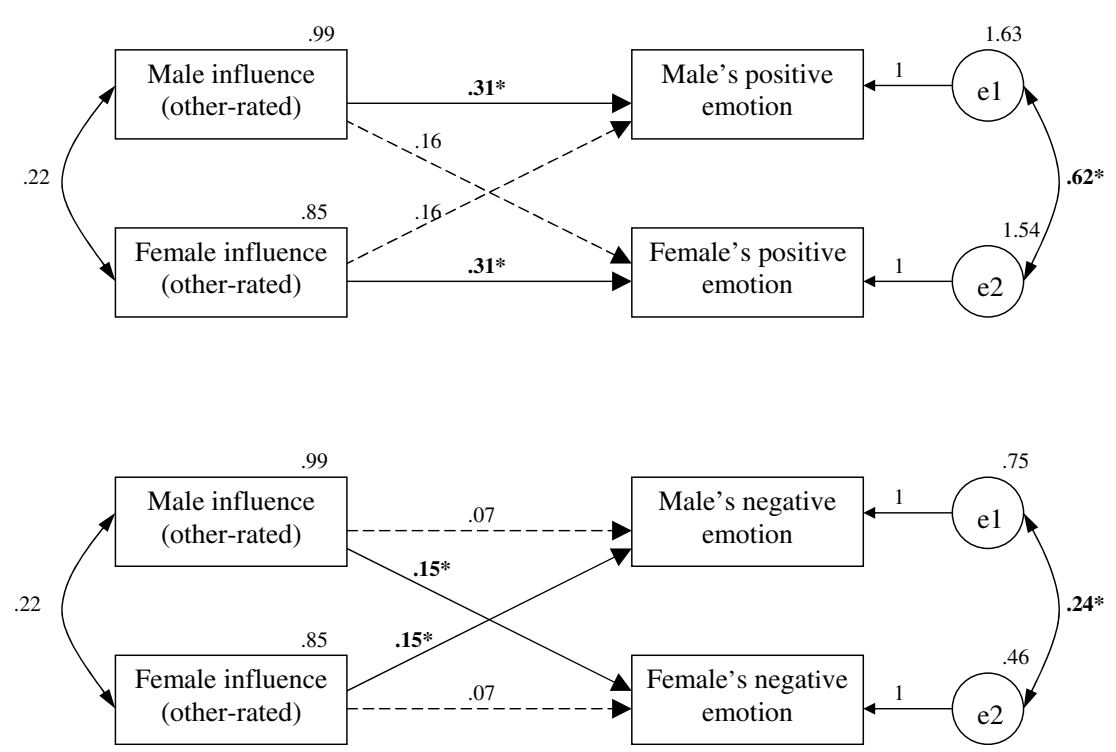

Fig. 1. Path-analytic model: Actor and partner effects of power on positive and negative emotional experience. Note. Bolded paths and starred weights are significant at the ${ }^{*} p<.05$ level.

their partner experienced more negative emotion across six different conversations.

Because partners rated only one another's influence (and not their own), it is unclear whether the perceptual source of actor and partner power differentially influences emotion. Actor effects of power might be due to the experience of power (self-report) or being seen as powerful by a partner (other-report). Partner effects of power might be due to perceiving a partner as powerful (other-report) or having a partner who views him or herself as powerful (self-report). In Study 2, we compare self-report and other-report measures for both actor and partner power.

\section{Study 2: Actor and partner effects of self- and other-reported power}

In the second study, we tested our power-emotion hypotheses amongst dyads in which participants were experimentally assigned to have high or low power. We expand upon Study 1 by not only examining actor and partner sources of power, but by also examining selfand partner-reports of both of these sources of power. Within dyadic interactions, actor and partner effects of power can be measured with self- and other-report, yielding four possible measurements of power: Actor effects measured with self-reports (the individual's reports of her or his own power) and other-reports (the partner's report of the individual's power), and partner effects measured with self-reports (the partner's reports of his or her own power) and other-reports (the individual's reports of the partner's power). Finally, as influence and control can be distinguished (Fiske \& Berdahl, 2007), we extend Study 1 by operationalizing power in terms of experimentally manipulated expertise and evaluative power (French \& Raven, 1959; Goodwin, Gubin,
Fiske, \& Yzerbyt, 2000). We examine whether the actor effect of power on positive emotion and the partner effect of power on negative emotion replicate across both low and high power role assignments.

\section{Methods}

\section{Participants}

Participants were 82 undergraduate students (41 women) enrolled in an introductory psychology course. Students' ages ranged from 18 to 25 years of age and 92\% were European American. Participants' data were reanalyzed from a previous study of manipulated power and flirtation. The original study had 118 participants and we reanalyze the data from participants assigned to high and low power roles (Gonzaga, Keltner, \& Ward, submitted for publication).

\section{Procedures}

Participants were randomly assigned to a high or low power role in a dyad with a member of the opposite sex. The high power participant had the role of interviewer (gaining procedural information and personal information about the partner) and the ability to judge the partner at the end of the interaction. The high power partner arrived at the laboratory $15 \mathrm{~min}$ before the other participant, by design, and received the instructions for the study in order to guide the low power partner through the study. When the low power partner arrived and was seated across from the high power partner, the experimenter informed the participants that the study was concerned with language and pronunciation, and that due to a scheduling error the later arriving (low power) partner had arrived late and to save time the early (high power) partner had been given instructions and would guide the experiment. 
Participants were given nine questions from the book "Questions for the Game of Life" and the high power partner was instructed to ask the low power partner each of the questions over a 10-min period (e.g., "If you could have a dinner party with one person from history, who would you choose, and why?", "If you could have been a lover of any person in history, who would you choose and why?"). Finally, participants completed the same teasing task used in Study 1. Participants were told that their teases would be evaluated, but as a "technical requirement" of the study, only the high power partner would evaluate the low power partner's tease. At the end of the teasing exercise, participants reported their emotions.

\section{Measures}

Social power. Participants rated both their own social power ("power you had during the interaction", "control you had during the interaction"; $\alpha=.90$ ) and their partner's social power ("power your partner had during the interaction", "control your partner had during the interaction"; $\alpha=.86$ ) on a scale from 1 ("none") to 7 ("an extreme amount").

Emotions. Discrete emotion items relevant to a stranger interaction (e.g., interest, self-consciousness) were generated by the second author. Participants reported their experience of emotions after teasing their partners on a scale from 1 ("none") to 7 ("an extreme amount"). Categorization of items as positive or negative was determined with principal components analysis with varimax rotation (see Table 2 for items and factor loadings). The eigenvalues and scree plot (Cattell, 1966) suggested a two factor solution (explaining $46 \%$ of the variance). Both the positive emotion composite and negative emotion composite were reliable $(\alpha=.88$, $m=3.27, S D=1.13 ; \alpha=.88, m=2.70, S D=1.02$, respectively). The positive and negative emotion composites were not significantly correlated $(r=-.15, p>.10)$.

Interdependence of dyadic data. Dyads were treated as distinguishable on the basis of power role assignment. Selfratings of power within dyads were positively correlated $(r=.34, p<.05)$, so hypotheses were tested at the dyadic level using the analytical approach outlined in Study 1. Paths for low and high role power individuals were allowed to vary in order to detect differences by assigned role.

\section{Results}

The power manipulation had a significant effect on both self-rated power and on ratings of partner power. Participants assigned to a low power role rated themselves lower in power $(m=3.66, S D=1.19)$ than did participants assigned to a high power role $(m=5.09, S D=1.45$, $F(1,80)=23.65, p<.05, d=1.08)$. Further, participants assigned to a low power role were rated by their partners as less powerful ( $m=3.02, S D=1.34)$ than were participants assigned to a high power role $(m=4.37$,
Table 2

Study 2: Positive and negative emotion composites

\begin{tabular}{|c|c|c|}
\hline Discrete emotions & Factor loading (I) & Factor loading (II) \\
\hline \multicolumn{3}{|l|}{ Positive } \\
\hline Amusement & -.24 & .75 \\
\hline Curious & -.20 & .64 \\
\hline Enjoyment & -.20 & .80 \\
\hline Enthusiastic & -.18 & .70 \\
\hline Happiness & -.23 & .80 \\
\hline Interested & .00 & .69 \\
\hline Involved & .00 & .57 \\
\hline Pride & .00 & .44 \\
\hline Stimulated & .21 & .72 \\
\hline \multicolumn{3}{|l|}{ Negative } \\
\hline Anger & .52 & .00 \\
\hline Anxious & .66 & .11 \\
\hline Concern & .59 & .00 \\
\hline Contempt & .38 & .00 \\
\hline Discomfort & .70 & -.14 \\
\hline Disgust & .51 & -.15 \\
\hline Embarrassment & .79 & .00 \\
\hline Guilt & .52 & .12 \\
\hline Intimidated & .73 & .00 \\
\hline Sadness & .41 & .00 \\
\hline Self-conscious & .74 & .00 \\
\hline Shame & .67 & .00 \\
\hline Tension & .77 & -.10 \\
\hline \multicolumn{3}{|l|}{ Cross-loaded } \\
\hline Attracted & .39 & .67 \\
\hline Desire & .43 & .52 \\
\hline Love & .32 & .42 \\
\hline Positive & -.36 & .73 \\
\hline Romantic & .34 & .64 \\
\hline Eigenvalues & 6.36 & 5.94 \\
\hline
\end{tabular}

Note. The items "shy", "awkward", and "outgoing" were also measured in the questionnaire but were not included in the factor analyses with emotion words because they are behavioral traits (Cheek \& Melchior, 1990; John, 1990). The item "comfortable" loaded negatively as a negative emotion and not as a positive emotion in a preliminary factor analysis, and so only "discomfort" was retained in the negative emotion composite to reduce redundancy. Items having cross-loadings higher than .32 were not included in the composites (Costello \& Osborne, 2005; Tabachnick \& Fidell, 2001).

$S D=1.08, F(1,80)=25.01, p<.05, d=1.41)$. Dyad members that were assigned a low power role were rated below the midpoint on power $(m=3.34, S D=.90, t=-4.680$, $p<.05$ ) and dyad members that were assigned a high power role were rated above the midpoint on power $(m=4.73, S D=.92, t=5.03, p<.05)$.

\section{Positive emotion}

A path analysis was designed in which both partners' self-rated and other-rated power predicted their own positive emotion and their partner's positive emotion (Fig. 2). The model fit the data well $\left(\chi^{2}(2)=1.73, p=.42\right.$, $\mathrm{TLI}=1.23$, RMSEA $=.000$ ). The paths from self-rated power to positive emotion were the only significant parameters, indicating that as in Study 1, individuals who had more power experienced more positive emotion (an actor effect). Only the individual's perception of his or her own 


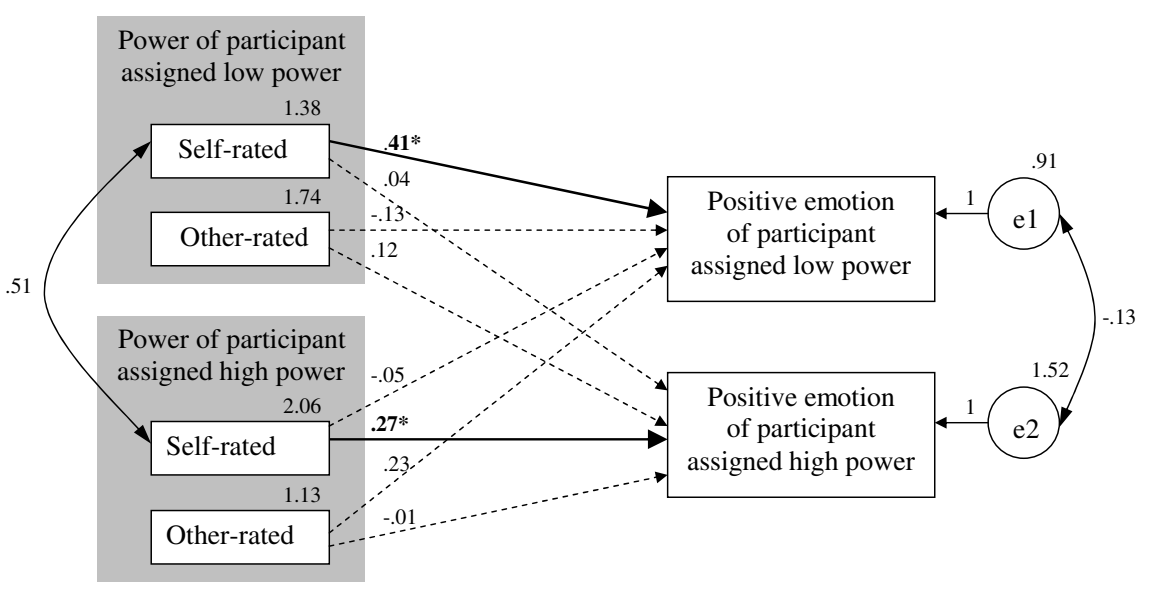

Fig. 2. Path-analytic model: Actor and partner effects of self- and other-rated power on positive emotional experience. Note. Bolded paths and starred weights are significant at the ${ }^{*} p<.05$ level. Nonsignificant covariances $(p>.10)$ between power ratings are not included in the figure. Other-ratings for the low power role participant refer to the rating made by the high power participant. Other-ratings for the high power role participant refer to the rating made by the low power participant.

power (self-report) predicted the experience of positive emotion and this effect held across power role assignments. In an additional model with two multiplicative terms (one for self-rated power and one for other-rated power) held equal to one another, none of the parameters from the interaction terms to emotion was significant.

\section{Negative emotion}

Next, a path analysis was designed in which both partners' self-rated and other-rated power predicted their own negative emotion and their partner's negative emotion (Fig. 3). The model fit the data well $\left(\chi^{2}(2)=1.73\right.$, $p=.42$, TLI $=1.27$, RMSEA $=.000$ ). As in Study 1 , the individual's negative emotion was predicted by the partner's social power (a partner effect), however this was only the case for individuals with a partner assigned to a high power role. In an additional model with two multiplicative terms (one for self-rated power and one for other-rated power) held equal to one another, none of the parameters from the interaction terms to emotion was significant. Both the partner's self-reported power and the individual's perception of the partner's power (other-report) affected the individual's experience of negative emotion.

\section{Discussion}

Replicating the findings from Study 1, actor power was associated with increased positive emotion, whereas partner power was associated with increased negative emotion. Extending Study 1, the current study documented these actor and partner effects with both self-reports and otherreports. Only self-reported actor power was related to positive emotion, but both self-rated and other-rated partner power were associated with negative emotion. An examination of the differences between high and low power roles indicated that while the perception of a partner's power was associated with negative emotion for those in a low power role, there was no relationship between a partner's power and negative emotion for those in a high power role.

\section{General discussion}

Across two studies of social power within dyads, we documented consistent relations between actor power and positive emotion and partner power and negative emotion. These findings highlight the importance of studying both actor and partner power within social interactions. When both selfreports and other-reports were examined, self-reports of an individual's power were the important predictor of positive emotion. This suggests that it is the experience of power, and accompanying rewards and freedoms that influence positive emotion. However, this finding will need to be replicated as self-ratings were not measured in Study 1 and other-ratings may operate just as strongly as self-ratings in such interdependent relations (versus among strangers). Negative emotion was associated with both the individual's perceptions of the high power partner's power and the partner's experience of power. It appears that a partner's power represents threat and constraint, and this may be especially true when the partner occupies a formal high power role.

The findings generalized across two types of dyads (romantic partners and strangers) that differed in length of relationship and degree of intimacy. However, future work might explore whether these findings generalize to other types of relationships and instantiations of social power. It will also be important to study actor and partner effects of power within same-sex interactions, given that women and men experience social roles differently (Glick $\&$ Fiske, 1999), and respond differently to low power (Vescio, Gervais, Snyder, \& Hoover, 2005). In the current studies, male and female reports of power were similar and the effects of the power manipulation did not differ by gender, however we lacked sufficient sample size to rigorously test gender differences. Future studies of same-sex interactions and experimental assignments to power roles that match 


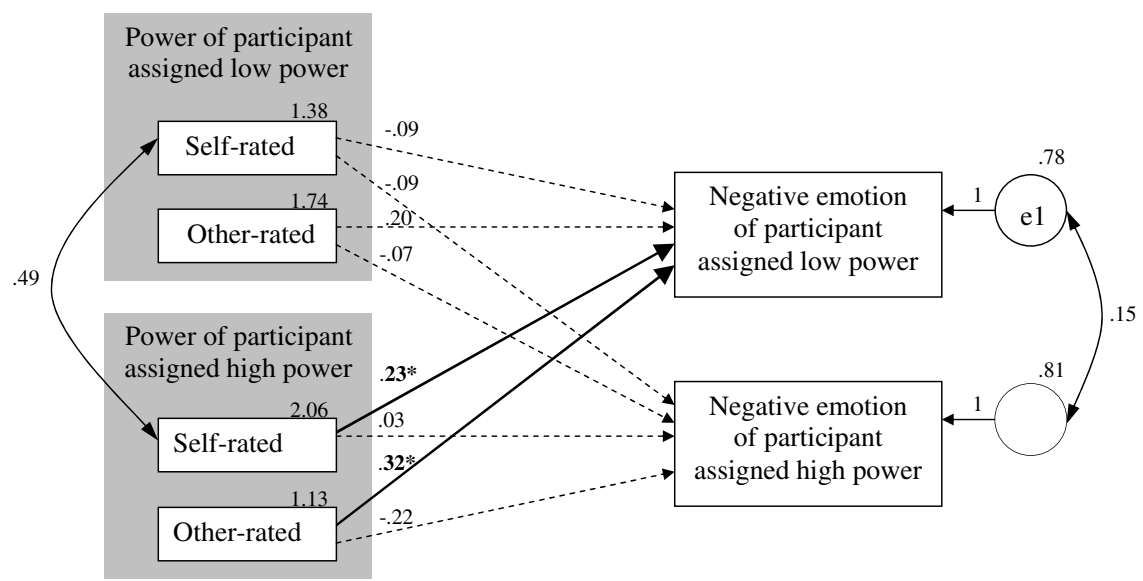

Fig. 3. Path-analytic model: Actor and partner effects of self- and other-rated power on negative emotional experience. Note. Bolded paths and starred weights are significant at the ${ }^{*} p<.05$ level. Nonsignificant covariances $(p>.10)$ between power ratings are not included in the figure. Other-ratings for the low power role participant refer to the rating made by the high power participant. Other-ratings for the high power role participant refer to the rating made by the low power participant.

and do not match self-construals could help illuminate the relationship between gender and power.

The current studies examined two instantiations of social power: Perceived influence within romantic relationships and perceived power within roles based upon expertise and evaluation. The approach in Study 1 is in keeping with French and Raven (1959) who defined power as "potential influence". However, others have conceptualized social power as asymmetrical control over another person's outcomes, or "outcome dependency" (Dépret \& Fiske, 1999; Kipnis, 1976; Thibaut \& Kelley, 1959) and distinguish between influence and control over valued resources (Fiske \& Berdahl, 2007). Study 2 operationalized power in terms of control over a social outcome (evaluation), but it will be important for future research to explore the actor and partner effects of power on emotion where power is operationalized in terms of control over material resources and other valued outcomes.

The current work focused on the subjective experience of social power within dyadic relationships. In Study 2, the experimental manipulation of high and low power was zero-sum as in most studies of power to date. Therefore, we used the continuous self- and other-perception measures to examine actor and partner effects. However, future experimental work might compare actor and partner effects of power by creating conditions in which both partners have power over one another, neither partner has power over the other, and where partners have asymmetric power. While the current studies did not uncover interaction effects, suggesting that actor and partner effects of power are not qualified by the degree of asymmetry in power relations, future experimental work should consider this issue.

The present research examined models of social power preceding emotional experience. However, it has also been found that emotional experience and display can affect social status (Tiedens, 2001). Future studies of individual differences and experimental manipulations of power in the context of longitudinal design should examine bidirec- tional relationships between power and emotion. These studies could also inform our understanding of changes in power distribution within relationships. The current work demonstrated a non-zero-sum, positive relationship between partners' power. Other studies have examined social power in an experimental setting in which social power by definition is zero-sum (Anderson \& Berdahl, 2002). Specifying when power relations between actor and partner are non-zero sum, negatively correlated, or positively correlated is essential to understanding the many kinds of power relations.

In sum, the current work highlights the importance of studying power within dyadic interactions, and the benefits of using dyadic statistical techniques for isolating actor effects and partner effects of social power. These findings speak to the importance of moving beyond the study of power within the individual (linking self-reports of power to the individual's behavior), and the importance of examining both actor effects (i.e., the individual's power) and partner effects (e.g., the romantic partner's power). These findings raise numerous questions. Do the documented effects of high social power, such as increased reliance upon stereotypes or more disposition-consistent behavior, find their origins in the individual's own sense of power (Chen et al., 2001; Vescio et al., 2005)? Similarly, do the effects of low social power, such as increased accuracy in social judgment or increased health problems, have their origins in others' power (Adler, 2003; Fiske, 1993)? Future research on social power within dyads can benefit from the theoretical and methodological distinction between actor and partner power.

\section{References}

Acitelli, L. K., Kenny, D. A., \& Weiner, D. (2001). The importance of similarity and understanding of partners' marital ideals to relationship satisfaction. Personal Relationships, 8(2), 167-185.

Adler, N. E. (2003). The role of psychosocial processes in explaining the gradient between socioeconomic status and health. Current Directions in Psychological Science, 12(4), 119-123. 
Anderson, C., \& Berdahl, J. L. (2002). The experience of power: Examining the effects of power on approach and inhibition tendencies. Journal of Personality and Social Psychology, 83, 1362-1377.

Anderson, C., \& Galinsky, A. D. (2006). Power, optimism, and risktaking. European Journal of Social Psychology, 36, 511-536.

Arbuckle, J. (1994). Amos 4 [Computer software]. Chicago: Smallwaters Corp.

Ashby, F. G., Isen, A. M., \& Turken, A. U. (1999). A neuropsychological theory of positive affect: And its influence on cognition. Psychological Review, 106(3), 529-550.

Berdahl, J. L., \& Martorana, P. (2006). Effects of power on emotion and expression during a controversial discussion. European Journal of Social Psychology: Special Issue on Social Power and Group Processes, 36, 497-509.

Berscheid, E., Snyder, M., \& Omoto, A. M. (1989). The Relationship Closeness Inventory: Assessing the closeness of interpersonal relationships. Journal of Personality and Social Psychology, 57(5), 792-807.

Brauer, M., \& Bourhis, R. Y. (2006). Social power. European Journal of Social Psychology, 36(4), 601-616.

Butler, D., \& Geis, F. L. (1990). Nonverbal affect responses to male and female leaders: Implications for leadership evaluations. Journal of Personality and Social Psychology, 58, 48-59.

Cacioppo, J. T., \& Berntson, G. G. (1994). Relationship between attitudes and evaluative space: A critical review, with emphasis on the separability of positive and negative substrates. Psychological Bulletin, $115(3), 410-423$.

Cattell, R. B. (1966). The scree test for the number of factors. Multivariate Behavioral Research, 1, 245-276.

Carver, C. S., \& White, T. L. (1994). Behavioral inhibition, behavioral activation, and affective responses to impending reward and punishment: The BIS/BAS Scales. Journal of Personality and Social Psychology, 67(2), 319-333.

Cheek, J. M., \& Melchior, L. A. (1990). Shyness, self-esteem, and selfconsciousness. In H. Leitenberg (Ed.), Handbook of social and evaluation anxiety (pp. 47-84). New York: Plenum Publishing.

Chen, S., Lee-Chai, A. Y., \& Bargh, J. A. (2001). Relationship orientation as a moderator of the effects of social power. Journal of Personality and Social Psychology, 80(2), 173-187.

Cook, W. L. (2001). Interpersonal influence in family systems: A social relations model analysis. Child Development, 72(4), 1179-1197.

Copeland, J. T. (1994). Prophecies of power: Motivational implications of social power for behavioral confirmation. Journal of Personality and Social Psychology, 67, 264-277.

Costello, A.B., \& Osborne, J.W. (2005). Best practices in exploratory factor analysis: Four recommendations for getting the most from your analysis. Practical Assessment, Research \& Evaluation, 10(7), 1-9. Available from: http://pareonline.net/getvn.asp?v=10\&n=7.

Côté, S., \& Moskowitz, D. D. (2002). How are moods instigated at work? The influence of relational status on mood. In W. J. Zerbe, N. Ashkanasy, \& C. Hartel (Eds.), Managing emotions in organization (pp. 111-134). Armonk, NY: M.W. Sharpe.

Davidson, R. J. (1992). Emotion and affective style: Hemispheric substrates. Psychological Science, 3, 39-43.

Dépret, E., \& Fiske, S. T. (1999). Perceiving the powerful: Intriguing individuals versus threatening groups. Journal of Experimental Social Psychology, 35(5), 461-480.

Emerson, R. M. (1964). Power-dependence relations: Two experiments. Sociometry, 27(3), 282-298.

Fiske, S. T. (1993). Controlling other people: The impact of power on stereotyping. American Psychologist, 48(6), 621-628.

Fiske, S. T., \& Berdahl, J. L. (2007). Social power. In A. Kruglanski \& E. T. Higgins (Eds.), Social psychology: A handbook of basic principles (2nd ed.). New York: Guilford.

French \& Raven, B. (1959). The bases of social power. In D. Cartwright (Ed.), Studies in social power (pp. 150-167). Oxford, England: University of Michigan.

Galinsky, A. D., Gruenfeld, D. H., \& Magee, J. C. (2003). From power to action. Journal of Personality and Social Psychology, 85(3), 453-466.
Gonzaga, G.C., Keltner, D., \& Ward, D. (submitted for publication). Power and flirtation: The perils of inappropriate approach.

Gonzalez, R., \& Griffin, D. (1999). The correlation analysis of dyad-level data in the distinguishable case. Personal Relationships. Special Methodological and Data Analytic Advances, 6(4), 449-469.

Goodwin, S. A., Gubin, A., Fiske, S. T., \& Yzerbyt, V. Y. (2000). Power can bias impression processes: Stereotyping subordinates by default and by design. Group Processes \& Intergroup Relations, 3(3), 227-256.

Glick, P., \& Fiske, S. T. (1999). Gender, power dynamics, and social interaction. In M. M. Ferree, J. Lorber, \& B. B. Hess (Eds.), Revisioning gender. The gender lens (pp. 365-398). Thousand Oaks, CA: Sage Publications, Inc.

Gray, J. A. (1987). The neuropsychology of emotion and personality. In S. M. Stahl, S. D. Iverson, \& E. C. Goodman (Eds.), Cognitive neurochemistry (pp. 171-190). Oxford: Oxford University Press.

Guinote, A. (2007). Power affects basic cognition: Increased attentional inhibition and flexibility. Journal of Experimental Social Psychology, 43(5), 685-697.

Guinote, A., Judd, C. M., \& Brauer, M. (2002). Effects of power on perceived and objective group variability: Evidence that more powerful groups are more variable. Journal of Personality and Social Psychology, 82, 708-721.

Hecht, M. A., \& LaFrance, M. (1998). License or obligation to smile: The effect of power and sex on amount and type of smiling. Personality and Social Psychology Bulletin, 24, 1332-1342.

John, O. P. (1990). The "Big Five" factor taxonomy: Dimensions of personality in the natural language and in questionnaires. In L. A Pervin (Ed.), Handbook of personality: Theory and research. New York: Guilford.

Keltner, D., Gruenfeld, D. H., \& Anderson, C. (2003). Power, approach and inhibition. Psychological Review, 110(2), 265-284.

Keltner, D., Young, R. C., Heerey, E. A., Oemig, C., \& Monarch, N. D. (1998). Teasing in hierarchical and intimate relations. Journal of Personality and Social Psychology, 75(5), 1231-1247.

Kenny, D. A., Kashy, D. A., \& Cook, W. L. (2007). The analysis of dyadic data. New York: Guilford Press.

Kipnis, D. (1976). The powerholders. Chicago, IL: University of Chicago Press.

Lawler, E. J., \& Bacharach, S. B. (1979). Power dependence in individual bargaining: The expected utility of influence. Industrial \& Labor Relations Review, 32(2), 196-204.

Lewin, K. (1951). Field theory in social science: Selected theoretical papers. Oxford, England: Harpers.

Overbeck, J. R., \& Park, B. (2001). When power does not corrupt: Superior individuation processes among powerful perceivers. Journal of Personality and Social Psychology, 81, 549-565.

Smith, P. K., \& Trope, Y. (2006). You focus on the forest when you're in charge of the trees: Power priming and abstract information processing. Journal of Personality and Social Psychology, 90, 578-596.

Tabachnick, B. G., \& Fidell, L. S. (2001). Using multivariate statistics. Boston: Allyn and Bacon.

Thibaut, J. W., \& Kelley, H. H. (1959). The social psychology of groups. New York: Wiley \& Sons, Inc.

Tiedens, L. Z. (2001). Anger and advancement versus sadness and subjugation: The effect of negative emotion expressions on social status conferral. Journal of Personality and Social Psychology, 80, 86-94.

Vescio, T. K., Snyder, M., \& Butz, D. A. (2003). Power in stereotypically masculine domains: A social influence strategy $\times$ stereotype match model. Journal of Personality and Social Psychology, 85(6), 1062-1078.

Vescio, T. K., Gervais, S. J., Snyder, M., \& Hoover, A. (2005). Power and the creation of patronizing environments: The stereotype-based behaviors of the powerful and their effects on female performance in masculine domains. Journal of Personality and Social Psychology, 88(4), 658-672.

Watson, D., Clark, L. A., \& Tellegen, A. (1988). Development and validation of brief measures of positive and negative affect: The PANAS scales. Journal of Personality and Social Psychology, 54(6), 1063-1070. 